\title{
İş güvenliği uzmanlarının tehlike algıları üzerinde etkili olan faktörler: İnşaat sektöründe bir uygulama
}

\author{
Tülay Çivící1,*, Gözde ÇALIM ${ }^{2 \dagger}$ \\ ${ }^{1}$ Balıkesir Üniversitesi Mimarlık Fakültesi, Mimarlık Bölümü, Çağış kampüsü, Balıkesir

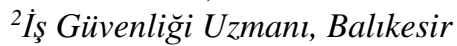 \\ Geliş Tarihi (Recived Date): 28.02 .2018 \\ Kabul Tarihi (Accepted Date): 09.08.2018
}

\section{Özet}

Bu çalışmada iş güvenliği uzmanlarının tehlike algıları ile çalışma ortamına ilişkin algl, güvenlik eğitimi, yönetimin güvenlik tutumu faktörlerinin ilişkisi incelenmiştir. Bu amaç için Balıkesir ili kapsamında inşaat şantiyelerinde çalışan iş güvenliği uzmanları tarafindan yanıtlanmak üzere bir anket çalışması düzenlenmiştir. 74 iş güvenliği uzmanı tarafından yanıtlanan anket ampirik olarak değerlendirilmiştir. Bulgular, güvenlik eğitimleri ve yönetimin tutumunun iş güvenliği uzmanlarının tehlike algılarını etkilediğini göstermektedir.

Anahtar kelimeler: İnşaat sektörü, iş güvenliği uzmanı, tehlike algısl.

\section{The factors effecting perceived hazard of occupational safety axpert: An applications in construction industry}

In this study the relationships between hazard of occupational safety experts and work environment on perceved safety, safety training, management attitude are investigated. For this purpose, a questionnaire study was survey to be answered by occupational safety experts in construction sites of Ballkesir. These survey were empirical tested by a survey of 74 occupational safety experts. The research findings reveal that perceived hazard and safety training, management attitude positively affect

Keywords: Constuction industry, occupational safety experts, perceved hazards.

\footnotetext{
* Tülay ÇIVİCI, tulay@ balikesir.edu.tr, https://orcid.org/0000-0002-5764-7951

Gözde ÇALIM, gzdeclm@ gmail.com, https://orcid.org/0000-0003-0303-2940

† Bu çalışma Gözde ÇALIM'ın dönem projesi’nden esinlenerek yapılmıştır.
} 


\section{Giriș}

İnşaat projeleri çok disiplinli ve bir çok organizasyonun birlikte çalışmasını gerektiren bir çalışma ortamında gerçekleşmektedir [1]. Bu çalışma ortamında inşaat projelerinin uygulama sürecinin, karmaşık, dinamik, belirsiz, değişken ve birbirinden farklı çalışma koşullarını içeren insan odaklı yapısı iş güvenliği problemlerinin yaşanmasını da kaçınılmaz kılmaktadır [2].

Yapılan çalışmalar iş güvenliğinin inşaat projelerinin tasarım aşamasından başlayarak tüm aşamalarında sistematik olarak değerlendirilmesi gereken bir konu olduğunu göstermektedir [3]. Çakar ve Kanoğlu [2] çalışmasında, tasarım aşamasındayken müşterilerin talepleriyle şekillenen proje ve onu oluşturan detayların, iş güvenliği problemlerinin meydana gelmesinde ilk adımı oluşturduğunu, proje başladıktan sonraki süreçte ise, projede yapılan değişiklikler dolayısıyla sürecin kısalması ve işin hızlandırılmasına yönelik proje değişikliklerinin iş güvenliği problemlerinin oluşmasında tetikleyici faktörleri meydana getirdiğini öne sürmektedir. Canpolat vd. [4] çalışmasında, proje uygulama sürecinde iş güvenliği için alınacak güvenlik önlemlerinin kimler tarafından nasıl yerine getirileceğinin projelendirme aşamasında planlanması gerektiğini vurgulamıştır. Gürcanlı [5] çalışmasında, tehlike analizlerinin tasarım aşamasında yapılamasının önemini vurguladığı çalışmasında, tasarım değişiklikleri ile risklerin azaltılarak tehlikelerin ortadan kaldırılabileceğini ileri sürmüş, kişisel koruyucu donanımların güvenlik önlemleri sıralamasında son sırada yer almasına rağmen tek güvenlik önlemi gibi algılanmasının sakıncalarına değinmiştir.

Baradan [6]' a göre; inşaat sektörü diğer sektörlerden farklı olarak her projenin birbirinden farklı olması ve bu yüzden her projede değişik çalışma koşullarında farklı risklerle karşı karşıya kalınması güvenlik problemlerinin başlıca nedenidir. İnşaat projelerinin uygulama alanı olan şantiyeler ise, işgücünün çeşitliliği, karmaşık iş kalemlerinin bir arada olması gibi kendine has doğası gereği tehlikelerle dolu bir çalışma ortamıdır [6]. Çalışma ortamında alınan güvenlik önlemleriyle tehlikelerin vereceği zararın önemli ölçüde azaltılabileceği bilinmektedir [7]. İş güvenliğinin sağlanmasında bütüncül bir yaklaşımla hareket edilerek, çalışma ortamı ve çalışanların tamamını kapsaması gerekliliktir. Fakat işçi sirkülasyonu fazladır bu da işçi eğitimini güçleştirmektedir. Uslu [8], inşaat şantiyelerindeki tehlikelerin doğru tespit edilebilmesinin önemli olduğunu, çalışma alanının da çalışanlarla birlikte değerlendirilmesi gerektiğini belirtmiştir. Demirkesen ve Arditti [9] çalışmasında iş güvenliği eğitiminin önemini vurgulamış, güvenli bir çalışma ortamında iş güvenliğinin eğitimle birlikte ele alınması gereken bir unsur olduğunu ifade etmiştir. Ercan [11] iş güvenliğinin sağlanmasında işverenin rolüne dikkat çekmiş, işçilerin güvenlik kurallarına uygun hareket edip etmediği, gerekli koruyucu materyalleri kullanıp kullanmadığının kontrol edilmesi, işçileri bu konuda bilinçlendirmek ve çalışma sahalarında iş güvenliği konusunda uzman kişilerin çalıștırılması gerektiği üzerinde durmuş, güvenliğinin sağlanmasında yapıcı, önleyici ve kapsayıcı bir tutum içinde olmaları gerekliliğini vurgulamıştır. 


\section{2. İș Güvenliği, tehlike kavramları ve iș güvenliği uzmanı}

İş güvenliği, işin yapılması sırasında çalışanların karşılaştığı tehlikelerin ortadan kaldırılması veya azaltılmasını öngörmektedir [12]. İş güvenliği kavramı, "işs yerinde çalışma koşullarından kaynaklanan çalışanlara yönelik tehlikelerin araştırılması ve önlenmesi amacıyla yapılan yöntemli çalışmaların tümü” olarak tanımlanmaktadır [13]. $\mathrm{Bu}$ yaklaşımla, çalışma ortamında tehlikenin tanımlanması iş güvenliğinin sağlanmasında ilk adımdır.

Tehlike, "İsyerinde var olan ya da dışarıdan gelebilecek, çalışanı veya işyerini etkileyebilecek zarar veya hasar verme potansiyeli" olarak tanımlanmıştır [14,15]. 2012 yılında yürürlüğe giren 6331 sayılı iş sağlı̆̆ ve güvenliği yasası ve bu yasaya bağlı olarak çıkarılan yönetmelikler, tehlikelerin araştırılması, tespit edilmesi ve yaratabilecekleri sonuçlara yönelik proaktif bir yaklaşımı ön plana çıkarmaktadır. 6331 sayılı yasa kamu ve özel tüm işyerlerinde tehlikelerin tespit edilmesi tehlikelerden kaynaklanacak kayıp, yaralanma ya da başka zararlı sonuç meydana gelme ihtimalinin ortaya konulması risk değerlendirmesi ön görmektedir. 6331 sayılı yasa kapsamında risk değerlendirmesi, "işveren tarafindan oluşturulan risk değerlendirmesi ekibi" nin yükümlülügündedir. Risk değerlendirme ekibinin önemli katılımcılarından biri iş güvenliği uzmanıdır.

İş güvenliği uzmanın tanımı, görev ve yetkileri 6331 sayılı yasanın 28512 sayılı yönetmeliğinde tanımlanmıştır. Buna göre iş güvenliği uzmanı, "işs sağllğg ve güvenliğ $i$ alanında görev yapmak üzere Bakanlıkça yetkilendirilmiş, iş güvenliği uzmanlığı belgesine sahip, Bakanlı ve ilgili kuruluşlarında çalışma hayatını denetleyen müfettişler ile mühendislik veya mimarlık eğitimi veren fakültelerin mezunları ile teknik eleman" olarak tanımlanmaktadır [14]. Tanımda yer alan teknik eleman; "teknik öğretmenler, fizikçi, kimyager veya biyolog unvanına sahip olanlar ile üniversitelerin iş sağlı̆̆l ve güvenliği lisans veya ön lisans programı mezunlarını" kapsamaktadır [14]. $\mathrm{Bu}$ kapsamda; iş güvenliği faaliyetlerine rehberlik edecek, tehlikeleri tanımlayacak, risklere yönelik tedbirler alacak, iş güvenliği eğitimlerini verecek bilgi ve etkinliğe sahip iş güvenliği uzmanları yetiştirilmesini ön görülmektedir. İş güvenliği uzmanlarının görevlendirmesinde ise, herhangi bir işyeri türü ayrımı yapılmaksızın çalışan sayısı ve çalışma bakanlığınca belirlenen iş yeri tehlike sınıflarına (çok tehlikeli, tehlikeli, az tehlikeli) uygunluğu dikkate alınmaktadır. Bu çalışma ortamında tehlikeler ile ilgili olarak farkındalığının en yüksek olması beklenen kişi iş güvenliği uzmanlarıdır [16].

İş güvenliği uzmanının iş sağlığı ve güvenliğini tehdit edebilecek muhtemel tehlikelerin belirlenmesi, yorumlanması sonucunda elde edilen verilerin risk çalışmalarına aktarılması, sonrasında alınacak güvenlik önlemlerinin belirlenmesi, uygulamasında önemli sorumlulukları bulunmaktadır. Bu durumda tehlikelerin tespitindeki yetersizlik iş güvenliğinin sağlanmasını güçleștirmektedir. Bu nedenle iş güvenliği uzmanlarının tehlike algısı iş güvenliğinin sağlanmasında önemli bir unsurdur. Tehlike algısı, çalışanı veya çalışma ortamını olumsuz etkileyebileceğine ilişkin ortaya çıkabilecek duruma karşı oluşan, algıyı ifade etmektedir.

$\mathrm{Bu}$ çalışmada inşaat şantiyelerinde hizmet veren iş güvenliği uzmanlarının tehlike algıları üzerinde çalışma ortamına ilişkin algıları, güvenlik eğitimi, yönetimin güvenlik 
tutumu faktörlerinin etkisi incelenmiştir. Bunun için çalışma kapsamında incelenen literatür çalışmaları [17-24] dikkate alınarak bir anket çalışması gerçekleştirilmiştir.

\section{Araştırma yöntemi}

Çalışma kapsamında belirtilen amaçlara ulaşabilmek için bir anket formu geliştirilmiştir. $\mathrm{Bu}$ anket formu iki bölümden oluşmaktadır. Birinci bölümde iş güvenliği uzmanlarının demografik özelliklerini belirlemeye yönelik sorular; ikinci bölümde, iş güvenliği uzmanlarının tehlike algısı, çalışma ortamına ilişkin algıları, güvenlik eğitimine ilişkin algıları, yönetimin güvenlik tutumuna yönelik ölçekler (sorular ve ifadeler) yer almaktadır[17-24]. Çalışmada yer alan tehlike algısı (TA); şantiye çalışma ortamı ve çalışanların karşılaşabileceği olumsuz durumların iş güvenliği uzmanları tarafından değerlendirilmesi, çalışma ortamında tehlikelerin sonuçlarının tahmin edilebilirliği ve şantiye organizasyonu yapılırken muhtemel tehlikelerin belirlenmesindeki güçlük/yetersizliklere ilişkin algılarını ölçmeye yönelik sorular ve ifadeler içermektedir. Çalışma ortamına ilişkin algı (OC); şantiye çalışma ortamının kendine özgü düzensiz ve karmaşık yapısının güvenli çalışma koşullarının sağlanmasında yarattığı güçlükleri tanımlamaya yönelik sorular ve ifadeleri içermektedir. Güvenlik eğitimi (EG); özel beceri isteyen görev ve kişisel koruyucu donanım ile ilgili verilen eğitimi, acil durumda yapılması gerekenlerle ilgili verilen eğitimi ve yönetimin çalışan eğitimine verdiği önemi, iş güvenliği uzmanlarının güvenlik eğitiminin çalışanların güvenlik bilincine katkısını ölçmeye yönelik sorular ve ifadeler yer almaktadır. Yönetimin güvenlik tutumu (YT) ise; yönetimin güvenlik önceliği, proaktif uygulamaları, kişisel koruyucu donanım kullanımı konusunda ve şantiye çalışma ortamında yasa ve prosedürlerin uygulanmasındaki duyarlılığı, çalışanlarla güvenlikle ilgili konularda işbirliği yaklaşımlarını, tehlikeli durum ve davranışların önlenmesinde tutumunu içeren soru ve ifadeler içermektedir [17-24].

Anketin ikinci bölümü için, inşaat sektörüne uyarlanan literatürde güvenilirliği test edilmiş ölçekler (sorular ve ifadeler) kullanılmıștır [17-24]. Ankette likert ölçeğine dayalı olarak verilen yanıtlar 1(hiç katılmıyorum)'den 5 (tamamen katılıyorum)' ye kadar derecelendirilmiştir. Çalışmanın örneklemi, inşaat şantiyeleri dikkate alınarak belirlenmiştir. Araştırmada hedef yanıtlayıcı kitlesi olarak Balıkesir ilinde inşaat şantiyelerinde çalışan iş güvenliği uzmanları belirlenmiştir. Hedef yanıtlayıcılara ziyaret ve e-mail yoluyla ulaşılmış, ankete katılmayı kabul edenlerin hazırlanan anket formunu yanıtlaması sağlanmıştır [25]. Anket çalışması için 95 iş güvenliği uzmanı ile temasa geçilmesine rağmen, 76'i anketi yanıtlamıştır. Anket formlarında 2' si eksik bilgiler nedeniyle değerlendirmeye alınmamıştır. $\mathrm{Bu}$ nedenle ankete katılan 74 (\%78) iş güvenliği uzmanın yanıtları değerlendirilmiştir.

Katılımcıların mesleki dağılımları tablo 1' de verilmiştir. Katılımcıların \% 50'sinin teknik eleman; \% 31'inin diğer mühendislikler (makine, elektrik, endüstri, jeoloji, maden, çevre mühendisi), \% 11'inin inşaat mühendisi, \% 8'inin mimar olduğu görülmektedir. 
Tablo 1. Ankete katılan iş güvenliği uzmanlarının meslek dağılımları.

\begin{tabular}{|l|l|l|l|}
\hline Meslek & Kadın & Erkek & TOPLAM(\%) \\
\hline Mimar & 3 & 2 & $6(\% 8)$ \\
\hline İnşaat Mühendisi & 2 & 6 & $8(\% 11)$ \\
\hline Diğer Mühendislikler & 7 & 14 & $23(\% 31)$ \\
\hline Teknik Eleman & 9 & 24 & $37(\% 50)$ \\
\hline TOPLAM & 21 & 46 & $74(\% 100)$ \\
\hline
\end{tabular}

Tablo 2' de katılımcılar çalıştığı inşaat şantiyesi türüne göre meslek gruplarının dağılımı yer almaktadır. Katılımcılardan alınan 50 yanıt üzerinden değerlendirildiğinde katılımcıların \% 63'nün konut inşaatı şantiyelerinde çalıştığı görülmektedir.

Tablo 2. Ankete katılan iş güvenliği uzmanlarının çalıştığı inşaat şantiyesi türü ve meslek grupları.

\begin{tabular}{|l|l|l|l|l|l|}
\hline Şantiye & Mimar & $\begin{array}{l}\text { İnşaat } \\
\text { Mühendisi }\end{array}$ & $\begin{array}{l}\text { Diğer } \\
\text { Mühendislikler }\end{array}$ & $\begin{array}{l}\text { Teknik } \\
\text { Eleman }\end{array}$ & $\begin{array}{l}\text { TOPLAM } \\
(\%)\end{array}$ \\
\hline Baraj & & 2 & & & $2(\% 2)$ \\
\hline Otoyol & & 1 & 1 & 2 & $4(\% 5)$ \\
\hline Eğitim Yapıları & 1 & & 6 & 5 & $12(\% 21)$ \\
\hline Endüstri Yapıları & 1 & 1 & 1 & 2 & $5(\% 9)$ \\
\hline Konut & 2 & 5 & 9 & 11 & $27(\% 63)$ \\
\hline
\end{tabular}

\section{Araştırma bulguları}

Çalışma kapsamında değerlendirilen iş güvenliği uzmanlarının tehlike algıları üzerinde çalışma ortamına ilişkin algı, güvenlik eğitimi, yönetimin güvenlik tutumu etkisi anket çalışmasından elde edilen veriler değerlendirilerek, istatistiksel olarak incelenmiştir. Anketlerden elde edilen verilerin istatistiksel analizi için istatistiksel analiz programı (SPSS 22) kullanılmış, veriler istatistiksel analiz programına (SPSS 22) girilmiş, ankette bulunan soruların güvenilirlik analizi yapılmıştır. Değişkenlerin ölçülmesinde sorulan ölçüm sorularının güvenirliliği, Cronbach alfa değerleri ile incelenmiştir (Tablo 3). Çalışma kapsamında incelenen değişkenlerin standart sapmaları $(\sigma)$ ve Cronbach Alpha $(\alpha)$ değerleri Tablo 3'de verilmiştir. Cronbach Alpha $(\alpha)$ değerinde 1'e yakın değerler ölçümün güvenilir olduğunu; 0.70 'in altında kalan değerler ise ölçümün güvenilir olmadığını ifade etmektedir [26]. Buna göre güvenilirlik (Cronbach Alpha) katsayısı tehlike algısı (TA) için 0.81, çalışma ortamına ilişkin alg1 (OC) için 0.74, güvenlik eğitimi (EG) için, 0.92, yönetimin güvenlik tutumu (YT) için ise 0.87 değerleri elde edilmiştir. Tablo 3'de verilen bu değerlerin değişkenlerin Cronbach Alpha $(\sigma)$ değerini karşıladığ1 görülmüştür. Yaş, meslek değerleri kategorik olarak ölçülen değişkenler için güvenilirlik analizi uygulanmamıştır [25]. 
Tablo 3. Araştırmada kullanılan değișkenlerin standart sapmaları $(\sigma)$ ve Cronbach Alpha $(\alpha)$

\begin{tabular}{|l|c|c|}
\hline Değişkenler & Standart Sapma $(\sigma)$ & Cronbach alfa $(\alpha)$ \\
\hline Yaş & 1.169 & - \\
\hline Meslek & 0.560 & - \\
\hline Tehlike Algısı (TA) & 0.667 & 0.81 \\
\hline Çalışma Ortamına ilişkin Algı (OC) & 0.934 & 0.74 \\
\hline Güvenlik Eğitimi (EG) & 0.849 & 0.92 \\
\hline Yönetim Güvenlik Tutumu (YT) & 0.619 & 0.87 \\
\hline
\end{tabular}

Değişkenlere ait güvenilirlik analizinden sonra korelasyon analizi ile değișkenler arası ilişki düzeyi belirlenmiştir. Pearson katsayısı (r) ile ifade edilen iki değişken arasındaki ilişki düzeyi -1 ve +1 arasında değişmekte, +1 'e yaklaştıkça pozitif güçlü bir ilişkinin varlığını -1'e yaklaştıkça ise negatif yönde güçlü bir ilişkin varlığını tanımlamaktadır [25]. Bu çalışma kapsamında yapılan anketlerden elde edilen veriler değerlendirilerek Tehlike Algısı, çalışma ortamına ilişkin algı, güvenlik eğitimi, yönetimin güvenlik tutumu faktörleri arasındaki ilişkileri araştırmak için korelasyon analizi yapılmıştır. Korelasyon analizi sonuçları Tablo 4'de verilmiştir. Buna göre; değişkenler arasında pozitif anlamlı bir ilişki vardır. En yüksek değer güvenlik eğitimi ve tehlike algısı $(r=0.782 ; p \leq 0.001)$ arasında bulunurken, en düşük değer güvenlik eğitimi ve yönetimin güvenlik tutumu $(\mathrm{r}=0.615 ; \mathrm{p} \leq 0.001)$ arasında bulunmuştur. Analiz bulgularında çalışma ortamına ilişkin algı değişkenin, diğer değişkenlerin hiçbiri ile anlamlı bir ilişkisine rastlanmamıştır.

Tablo 4. Değişkenler arasındaki korelasyon katsayıları.

\begin{tabular}{|l|l|l|l|l|}
\hline & \multicolumn{1}{|c|}{ TA } & \multicolumn{1}{|c|}{ OC } & \multicolumn{1}{c|}{ EG } & \multicolumn{1}{c|}{ YT } \\
\hline Tehlike Algısı (TA) & 1 & & & \\
\hline Çalışma Ortamına ilişkin Algı (OC) & 0.021 & 1 & & \\
\hline Güvenlik Eğitimi (EG) & $0.782^{* * *}$ & 0.092 & 1 & \\
\hline Yönetimin Güvenlik Tutumu (YT) & $0.775^{* * *}$ & 0.071 & $0.615^{* * *}$ & 1 \\
\hline
\end{tabular}

$\mathrm{p}^{* * *} \leq 0.001, \mathrm{p}^{* *} \leq 0.01, \mathrm{p}^{*} \leq 0.05$

$\mathrm{Bu}$ çalışma kapsamında tehlike algısı üzerinde, çalışma ortamına ilişkin algısının, güvenlik eğitimi, yönetimin güvenlik tutumunun etkisinin istatistiksel olarak değerlendirmek için regresyon analizi kullanılmıştır. İki veya daha çok değişken arasında herhangi bir ilişki olup olmadığı ve bu ilişkinin derecesini değerlendirmek üzere yapılan regresyon analizinde, bağımlı değişken (tehlike algısı) ile yaş, meslek, çalışma ortamına ilişkin algıları, güvenlik eğitimi, yönetimin güvenlik tutumu bağımsız değişkenleri ile ilişkileri ortaya konulmuştur.

SPSS 22 ile yapılan regresyon analizinin sonucu elde edilen değişkenlere ait patika katsayıları $(\beta)$ ve modelde yer alan bağımlı değişkene ait determinasyon katsayıları $\left(\mathrm{R}^{2}\right)$ özet halinde Tablo 5' de verilmiştir. Tablo 5' de yer alan, elde edilen değerler bağımlı değişkenlerin tehlike algısının açıklanmasında $\left(R^{2}=0.881 ; p \leq 0 ., 001\right)$ yeterli olabileceğini, istatistiksel olarak da anlamlı olduğunu göstermektedir. Bağımlı değişkenler için katılımcının mesleği $\beta_{1}=0.048$ ( $\left.\mathrm{p} \leq 0.524\right)$; yaşı $\beta_{2}=0.020$ ( $\mathrm{p} \leq 0.583$ ); 
çalışma ortamına ilişkin alg1 $\beta_{\mathrm{OC}}=0.004$ ( $\left.\mathrm{p} \leq 0.932\right)$; güvenlik eğitimi $\beta_{\mathrm{EG}}=0.370$ $(\mathrm{p} \leq 0.001)$; yönetimin güvenlik tutumu $\beta_{\mathrm{YT}}=0.380(\mathrm{p} \leq 0.524)$ olarak elde edilmiştir.

Tablo 5. Regresyon Analizi.

\begin{tabular}{|c|c|}
\hline $\begin{array}{l}\text { Tehlike Algısı (TA)= } \\
\text { (Bağımlı Değișken) }\end{array}$ & $\begin{array}{l}\text { Sabit }+\beta_{1} \text { meslek }+\beta_{2} \text { yaş }+ \\
\beta \text { oc Çalışma Ortamına ilişkin Alg } 1+ \\
\beta_{\text {EG Güvenlik Eğitimi (EG)+ }} \\
\beta_{\text {YT Yönetimin Güvenlik Tutumu }(Y T)+\text { e (hata sabiti) }}\end{array}$ \\
\hline
\end{tabular}

\begin{tabular}{|l||c||c||c|}
\hline $\begin{array}{l}\text { Tehlike Algısı (TA) } \\
\text { (Bağımlı Değişken) }\end{array}$ & $\begin{array}{l}\text { Standart Beta } \\
\text { Katsayısı }\end{array}$ & t Değeri & $\begin{array}{l}\text { Anlamlılık } \\
\text { Düzeyi } \\
(\mathrm{p})\end{array}$ \\
\hline Meslek & 0.048 & 0.641 & 0.524 \\
\hline Yaş & 0.004 & -0.085 & 0.583 \\
\hline Çalışma Ortamına ilişkin Algı (OC) & $\mathbf{0 . 3 7 0}$ & $\mathbf{5 . 6 4 1}$ & $\mathbf{0 . 0 0 0}$ \\
\hline Güvenlik Eüitimi (EG) & $\mathbf{0 . 3 8 0}$ & $\mathbf{3 . 3 8 0}$ & $\mathbf{0 . 0 0 0}$ \\
\hline Yönetimin Güvenlik Tutumu (YT) & & & \\
\hline $\mathrm{R}^{2}=0.881$ & & \\
\hline $\begin{array}{l}\mathrm{p}=0.000 \\
\mathrm{p}^{* * *} \leq 0.001, \mathrm{p}^{* *} \leq 0.01, \mathrm{p}^{*} \leq 0.05\end{array}$ & & \\
\hline
\end{tabular}

\section{Sonuçlar ve tartışma}

$\mathrm{Bu}$ çalışmada inşaat sektöründe çalışan iş güvenliği uzmanlarının tehlike algıları üzerinde çalışma ortamına ilişkin algıları, güvenlik eğitimi, yönetimin güvenlik tutumu faktörlerinin etkisi incelenmiştir. Yapılan istatistiksel analizler tehlike algısının açıklanmasında güvenlik eğitimi ve yönetimin güvenlik tutumunun etkili faktörler olduğunu göstermektedir.

Çalışma bulguları, güvenlik eğitiminin iş güvenliği uzmanlarının tehlike algıları üzerinde etkili olabileceğini göstermektedir. Bunun nedeni, alınan eğitim ile birlikte çalışanların iş güvenliği bilincinin artabileceği, iş güvenliğinin sağlanması için daha istekli ve katılımcı olmalarıdır. Çalışmanın bir başka bulgusu ise; yönetimin güvenlik tutumunun iş güvenliği uzmanlarının tehlike algıları üzerinde etkisinin olduğudur. Bunun nedeni ise, yönetimin iş güvenliği konusundaki tutumu iş güvenliğinin sağlanmasında bütünleştirici, kapsayıcı ve koruyucu bilinçle yaklaşmasının önemidir. İş güvenliğinin sağlanması, teknik süreçlerin (koruyucu önlemler, risk analizi, kaza oranları, gibi) ve kurumsal (yasa, kurum, standart, gibi) süreçlerin bütüncül olarak ele alınması ile mümkündür. Teknik ve kurumsal süreçlerin bütünleşmesi ise duyarlı, yapıcı, önleyici ve kapsayıcı bir yönetim anlayışını gerektirmektedir.

Çalışma bulgularında, iş güvenliği uzmanlarının tehlike algıları üzerinde çalışma ortamına ilişkin algının etkisinin varlığına ilişkin bir bulgu elde edilememiştir. İnşaat projelerinin birbirinden farklı, kendine özgü yapısı, bazı tehlikelerin ancak uzman mimar veya inşaat mühendisleri tarafından algılanabilir niteliktedir. Çalışmada inşaat şantiyelerinde çalışan iş güvenliği uzmanlarının çoğunlukla mimar veya inşaat 
mühendisi dışındaki meslek gruplarından olmaları nedeniyle çalışma ortamına ilişkin algılarında önemli farklılıklar olabileceğini, bu durumun istatistiksel bulguların anlamlılık düzeyini etkilediğini düşündürmektedir. Ayrıca 6331 sayılı kanun iş sağlığı ve güvenliği uzmanlarının görevlendirmelerini tehlike sınıfı üzerinden değerlendirmektedir. $\mathrm{Bu}$ durum yeterli eğitimine sahip bir iş güvenliği uzmanının tehlike sınıfı uygun olması durumunda inşaat sektöründe rol alabileceğini göstermektedir.

Sonuç olarak, iş güvenliği uzmanının iş sağlığı ve güvenliğini tehdit edebilecek muhtemel tehlikelerin belirlenmesi, yorumlanması sonucunda elde edilen verilerin risk çalışmalarına aktarılması, sonrasında alınacak güvenlik önlemlerinin belirlenmesi, uygulamasında iş güvenliği uzmanlarının önemli sorumlulukları bulunmaktadır. Bu görev ve sorumluluğun yerine getirilmesinde öncelikle tehlike algılarının nasıl ve neden etkilendiklerinin tespit edilmesi önemlidir. Sektöre ilişsin çalışma ortamının bilinmesi, çalışma ortamının çalışanlarla birlikte değerlendirilmesi (eğitimi, tutumu, yaklaşımı), mevcut durumu değerlendirilerek güvenlik problemlerinin çözüme yönelik gerçekçi ve uygulanabilir planlamaların hazırlanması, çalışanların ve yönetimin birbiriyle iletişim kurması, teknik ve kurumsal süreçlerin bütünleşmesi gibi birçok faktör iş güvenliğinin sağlanmasına olumlu etkileri olacaktır.

Çalışma sonucu elde edilen bulgular örneklem ile sınırlıdır. Bu çalışmanın örneklemi genişletilerek ulusal ölçekte katılımcıyı kapsaması sektör düzeyinde sonuçlara ulaşmayı sağlayacaktır.

\section{Kaynaklar}

[1] Lingard H., Zhang R.P., Blism As N., Wakefield R. \& Kleiner B.. Are We On The Same Page? Exploring Construction Professionals' Mental Models Of Occupational Health And Safety, 33, 73-84, Construction Management And Economics (2015).

[2] Çakar V. ve Kanoğlu A., İnşaat Sektörü İçin İş Güvenliği Enformasyon Sistemi Tasarımı 3. İşçi Sağlığı ve İş Güvenliği Sempozyumu, (2011)

[3] Ulukan Ş. E., Sağlık ve Güvenliği Tasarlamak, Mimarlık Dergisi, 384, (2015).

[4] Canpolat P., Çelik G. T., Oral E. L., Projelendirme ve Şantiye Yerleşim Projesinin Oluşturulması Aşamasında Hazırlanacak İş Sağlığı ve Güvenliği Planı ile İlgili Bir Öneri, 3. İşçi Sağlı̆̆ı ve İş Güvenliği Sempozyumu, (2011)

[5] Gürcanlı E., İnşaatlarda Tasarım Yoluyla İş Güvenliği, Türkiye Mühendislik Haberleri, 459, (2011).

[6] Baradan S., Türkiye İnşaat Sektöründe İş Güvenliğinin Yeri Ve Gelişmiş Ülkelerle Kıyaslanması, DEÜ Mühendislik Fakültesi Fen ve Mühendislik Dergisi, 8, 1, 87-100, (2006).

[7] Dal, M., Yorulmaz, İ., İnşaat Endüstrisi Uygulamalarında İş Sağlı̆̆ ve Güvenliği Açısından Hatalı Uygulamaların Değerlendirilmesi, 1. Uluslararası İş Güvenliği ve Çalışan Sağlığı Kongresi, 6-7 Mayıs, (2016).

[8] Uslu, B. V., İşletmelerde İş Güvenliği Performansı ve İş güvenliği Kültürü Algılamaları Arasındaki İlişki: Eskişehir İli Metal Sektöründe Bir Araştırma, Yüksek Lisans Tezi, Osmangazi Üniversitesi, Sosyal Bilimler Enstitüsü, Eskişehir, (2014). 
[9] Demirkesen, S. ve Arditti D., Yapı sektöründe iş güvenliği eğitimi, Türkiye Mühendislik Haberleri, 5, (2011).

[10] Ülkeryıldız E., İlal M. E. ve Kale S., İnşaat firmalarının iş güvenliği başarım düzeyinin ölçülmesine yönelik entropi tabanlı bir model, 3. İşçi Sağlığı ve İş Güvenliği Sempozyumu, (2011).

[11] Ercan, A., Türkiye'de yapı sektöründe işçi sağlığı ve güvenliğinin değerlendirilmesi, Politeknik Dergi, 13(1), 49-53, (2010).

[12] Demircioğlu, A.M., İş güvenliği uzmanlığ yönünden iş sağlığ1 ve güvenliği kanunu tasarısı taslağı' nın incelenmesi, Sicil, 5,918, (2007).

[13] Şahin M., Betonarme, çelik ve hafif çelik binalarda iş güvenliği risklerinin karşılaştırmalı analizleri, Yüksek Lisans Tezi, İstanbul Teknik Üniversitesi, (2012).

[14] İş sağlığı ve güvenliği kanunu, Resmi Gazete, 30.06.2012.

[15] Başbuğ, A., İşyerlerinde iş sağlığı ve güvenliği, (2013).

[16] Tülü M., İş sağlığ1 ve güvenliği hizmetlerinde isg profesyonellerinin alg1 ve beklentileri, Çalışma Sosyal Güvenlik Bakanlığı İş Sağlığı ve Güvenliği Genel Müdürlüğü, Ankara, (2014).

[17] Dursun, S., Güvenlik kültürünün güvenlik performansı üzerine etkisine yönelik bir uygulama, Doktora Tezi, Bursa Uludağ Üniversitesi, Sosyal Bilimler Enstitüsü, Yönetim ve Çalışma Psikolojisi Bilim Dalı, (2011).

[18] Mohamed, S., Safety climate in construction site environment, Journal of Construction Engineering and Management, 128, 375-384, (2002).

[19] Yıldız S. ve Yılmaz M., Türk inşaat sektöründe çalışanların güvenlik kültürü düzeyinin ve güvenlik performansı ile ilişkisinin incelenmesi, Politeknik Dergisi, 20, 1, 137-149, (2017).

[20] Zohar, D., Safety climate in industrial organizations: theoretical and applied implications, Journal of Applied Psychology, 65, 96-102, (1980).

[21] Zhou Z., Goh Y.M., Li Q., Overview and analysis of safety management studies in the construction industry, Safety Science, 72, 337-350, (2015).

[22] Lin S.H., Tang W.J., Miao J.Y., Wang Z. M., Wang P.X., Safety climate measurement at workplace in China:A validity and reliability assessment, Safety Science, 46, 1037-1046, (2008).

[23] Choudhry, R.M., Fang, D., ve Lingard, H., Measuring Safety Climate of a construction company, Journal of Construction Engineering and Management, 13, 9, 890-899, (2009).

[24] Türen U., Gökmen Y., Tokmak İ. ve Bekmezci M., Güvenlik iklimi ölçeğinin geçerlilik ve güvenilirlik çalışması, Süleyman Demirel Üniversitesi İktisadi ve İdari Bilimler Fakültesi Dergisi, 19(4),171-190, (2014).

[25] Çivici T., Mimari tasarım bürolarında çalışan mimarların mesleki tükenmişlik düzeylerini etkileyen demotivasyon faktörleri, Çukurova Üniversitesi Mühendislik Mimarlık Fakültesi Dergisi, 31(1), (2016).

[26] Van de Ven, A., Ferry, D., Measuring and assessing organizations, Wiley, NewYork, (1979). 